\title{
An Elasto-Plastic Stress Analysis of Simply Supported Aluminum Metal Matrix Composite Beams Under a Transverse Linearly Distributed Load by Use of Anisotropic Elasticity Theory
}

\author{
Ümran Esendemir \\ Department of Mechanical Engineering, Süleyman Demirel University, \\ Isparta, Turkey
}

\begin{abstract}
A beam is a structural element loaded transversely in gencral conditions. This loading causes shear forces and bending moment. In this study, an analytical elastoplastic stress analysis is carried out on simply supported stainless stecl fiber reinforced aluminum metal matrix composite beams under linearly distributed load using anisotropic elasticity theory. In the elasto-plastic solution, the material is assumed to be perfectly plastic. Sample problems are given for various angles analytically. The yielding begins at the upper and lower surfaces of the beam at the same distances from the ends. The intensity of residual stress component of $\sigma_{x}$ is maximum at the upper and lower surfaces but residual stress component of $\tau_{x y}$ is maximum on the $x$ axis of the beam. The composite beams can be strengthened by using the residual stresses.
\end{abstract}

Key Words: Residual stress, elasto-plastic stress analysis, metal-matrix composite, simply supported beam. linearly distributed load.

\section{INTRODUCTION}

Metal-matrix composites offer an increased service temperature and improved specific mechanical properties over existing metal alloys. They consist of a ductile, usually low density, matrix reinforced with elastic or ductile and strong fibers. Aluminum-matrix composites, which are particularly cited for their superior performance-to-weight advantage, have many applications in the aerospace and other industries. Many different technologies for production of metal-matrix composites have emerged over the years.

Chou et al. /1/ reviewed the work on fiber-reinforced metal-matrix composites explaining fabrication methods, mechanical properties, secondary working techniques and interfaces. Kaczmar et al. /2/ discussed the production methods and properties of metal matrix composite materials reinforced with dispersion particles, platelets, non-continuous (short) and continuous (long) fibres. Khatibzadeh and Piggott $/ 3 /$ investigated the effect of width on the mechanical properties of angleply laminates by using +45 balanced angle-ply laminates. Bahei-El-Din and Dvorak /4/ studied the elastic-plastic behaviour of symmetric metal-matrix composite laminates for the case of in-planc mechanical loading. Kang and Kang /5/ reviewed the work on the short fiber-reinforced aluminum composite matcrial, fabricated by stirring method and extruded at high temperatures at various extrusion ratios. Yeh and Krempl /6/ investigated the influence of cool-down temperature histories on the residual stress in fibrous metal-matrix composites. Sayman and Kayrıcı /7/ studied a low density polyethylene thermoplastic composite beam, reinforced with woven steel fibers, which is loaded by a single force at its free end. Esendemir 18/ carried out an clasto-plastic stress analysis in a thermoplastic composite beam of arbitrary orientation subjected to transverse uniformly distributed load by using an analytical solution. Esendemir /9/ carried out an analytical elasto-plastic stress analysis for 
a fiber-reinforced polymer matrix composite beam subjected to a linearly distributed load. Sayman $/ 10 /$ performed an elastic-plastic stress analysis in metalmatrix composite beam under a transverse force. Karakuzu and Özcan $/ 11 /$ determined residual stresses in an aluminum metal-matrix composite cantilever beam analytically. Küçük et al. /12/ carried out an elasticplastic stress analysis in an aluminum metal matrix composite beam supported from two ends with a force acting at the mid point. Elastic-plastic and residual stresses in metal matrix or thermoplastic composite cantilever beams were studied by using analytical methods $/ 13-16 /$.

In this study an analytical elastic-plastic stress analysis is carried out on metal matrix composite beams supported from two ends under transverse linearly distributed load in the $x-y$ plane.

\section{ELASTIC ANALYSIS}

The simply supported composite beam is subjected to a transverse linearly distributed load $q$, as shown in Figure 1. The angle between the first principal axis of the composite fibers and the $\mathrm{x}$ axis is $\theta$. The governing differential equation for an orthotropic beam in the plane stress case is given by Lekhnitskii / $7 /$.

$$
\begin{gathered}
a_{22} \frac{\partial^{4} F}{\partial x^{4}}-2 a_{26} \frac{\partial^{4} F}{\partial x^{3} \partial y}+\left(2 a_{12}+a_{66}\right) \frac{\partial^{4} F}{\partial x^{2} \partial y^{2}} \\
-2 a_{16} \frac{\partial^{4} F}{\partial x \partial y^{3}}+a_{1 !} \frac{\partial^{4} F}{\partial y^{4}}=0
\end{gathered}
$$

where $F$ is a stress function. Solutions of some anisotropic beams are given by Lekhnitskii /18/. The constants in Equation (1) are given by Jones/19/as,

$$
\left\{\begin{array}{l}
\varepsilon_{x} \\
\varepsilon_{y} \\
\gamma_{x y}
\end{array}\right\}=\left[\begin{array}{l}
a_{11} a_{12} a_{16} \\
a_{12} a_{22} a_{26} \\
a_{16} a_{26} a_{66}
\end{array}\right]\left\{\begin{array}{l}
\sigma_{x} \\
\sigma_{y} \\
\tau_{x y}
\end{array}\right\}
$$

where $a_{i i}$ are the components of the compliance matrix. The elements of compliance matrix are given as

$$
\begin{aligned}
& a_{11}=S_{11} m^{4}+\left(2 S_{12}+S_{66}\right) m^{2} n^{2}+S_{22} n^{4} \\
& a_{12}=S_{12}\left(n^{4}+m^{4}\right)+\left(S_{11}+S_{22}-S_{66}\right) n^{2} m^{2} \\
& a_{22}=S_{11} n^{4}+\left(2 S_{12}+S_{66}\right) n^{2} m^{2}+S_{22} m^{4} \\
& a_{16}=\left(2 S_{11}-2 S_{12}-S_{66}\right) n m^{3}-\left(2 S_{22}-2 S_{12}-S_{66}\right) n^{3} m \\
& a_{26}=\left(2 S_{11}-2 S_{12}-S_{66}\right) n^{3} m-\left(2 S_{22}-2 S_{12}-S_{66}\right) m^{3} n \\
& a_{66}=2\left(2 S_{11}+2 S_{22}-4 S_{12}-S_{66}\right) n^{2} m^{2}+S_{66}\left(n^{4}+m^{4}\right)
\end{aligned}
$$

$$
s_{11}=\frac{1}{E_{1}}, s_{12}=-\frac{v_{12}}{E_{1}}, S_{22}=\frac{1}{E_{2}}, S_{66}=\frac{1}{G_{12}}
$$

where $m=\cos \theta, n=\sin \theta$

Boundary conditions for this beam are given as,

$$
y=c \Rightarrow \sigma_{y}=0
$$

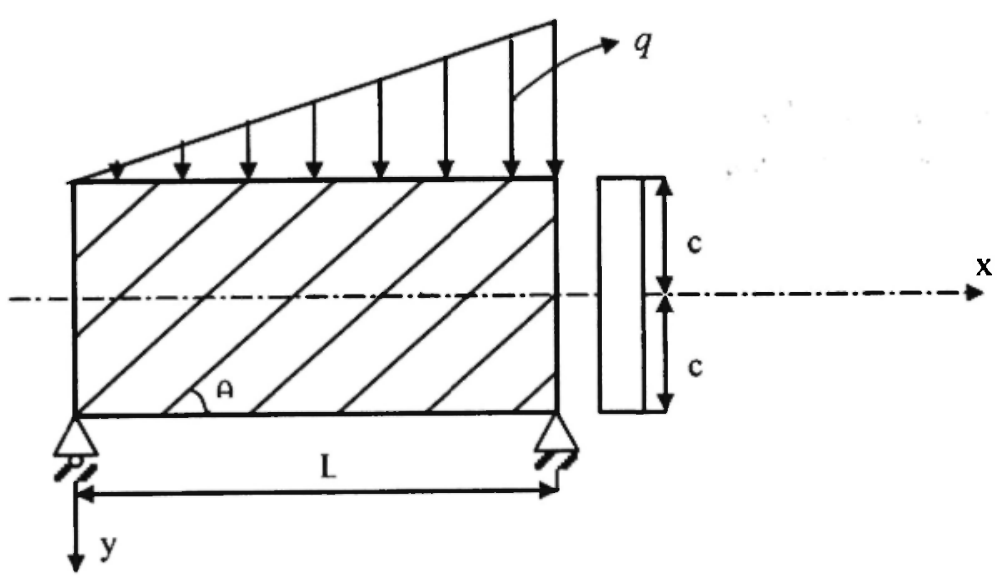

Fig. 1: Simply supported composite cantilever beam subjected to a linearly distributed load. 


$$
\begin{aligned}
& y=-c \Rightarrow \sigma_{y^{\prime}}=\frac{q_{o} x}{t L} \\
& y= \pm c \Rightarrow \tau_{x y}=0 \\
& x=0 \Rightarrow \int_{-c}^{c} \tau_{x y} t d y=\frac{q_{o} L}{6} \\
& x=L \Rightarrow \int_{-c}^{c} \tau_{x y} t d y=\frac{q_{o} L}{3} \\
& x=0 \Rightarrow \int_{-c}^{c} \sigma_{x} t d y=0 \\
& x=L \Rightarrow \int_{-c}^{c} \sigma_{x} t d y=0 \\
& x=0 \Rightarrow \int_{-c}^{c} \sigma_{x} t y d y=0 \\
& x=L \Rightarrow \int_{-c}^{c} \sigma_{x} t y d y=0
\end{aligned}
$$

where $t$ is the thickness of the beam. For satisfying both the differential equation and boundary conditions, the stress function $F_{6}$ is chosen as

$$
F_{6}=\frac{x y^{5}}{20} f_{6}+\frac{x^{3} y^{3}}{6} d_{6}+\frac{x^{2} y^{4}}{12} e_{6}
$$

Substituting Equation (1) gives

$$
\begin{aligned}
& -6 a_{16} d_{6}+2 a_{11} e_{6}=0 \\
& e_{6}=3 \frac{a_{16}}{a_{11}} a_{6}, \quad m=\frac{a_{16}}{a_{11}}
\end{aligned}
$$

and.

$$
\begin{aligned}
& \left(12 a_{12}+6 a_{66}\right) d_{6}-\left(8 a_{16}\right) 3 m d_{6}+6 a_{11} f_{6}=0 \\
& f_{6}=-2 n d_{6}, \quad n=\frac{1}{2} \frac{2 a_{12}+a_{66}-4 a_{16} m}{a_{11}}
\end{aligned}
$$

For satisfying all the boundary conditions we also select the stress function as second and third orders:

$$
\begin{aligned}
F= & \frac{d_{6} x^{3} y^{3}}{6}+\frac{f_{6} x y^{5}}{20}+\frac{d_{4} x y^{3}}{6} \\
& +\frac{t_{4} x^{3} y}{6}+\frac{a_{2} x^{2}}{2}+b_{2} x y
\end{aligned}
$$

$$
\begin{aligned}
\sigma_{x}= & \frac{\partial^{2} F}{\partial l^{2}}=d_{6} x^{3} y+f_{6} x y^{3}+d_{4} x y \\
\sigma_{y}= & \frac{\partial^{2} F}{c^{2}}=d_{6} x y^{3}+b_{4} x y+a_{2} \\
\tau_{x y}= & -\frac{\partial^{2} F}{\partial x c^{3} y}=-\frac{3}{2} d_{6} x^{2} y^{2}-\frac{1}{4} f_{6} y^{4} \\
& -\frac{1}{2} d_{4} y^{2}-\frac{i}{2} \dot{v}_{4} x^{2}-i_{2}
\end{aligned}
$$

From boundary conditions Eqn.(4) and (5)

$$
a_{2}=-\frac{q_{o} x}{2 L t}, \quad i_{4}-\frac{q_{o}}{2 t L c}-a_{6} c^{2}
$$

are obtained. From Eqn (4)

$$
b_{2}=-\frac{1}{20} f_{6} c^{4}-\frac{1}{6} d_{4} c^{2}-\frac{q_{o} L}{12 t c}
$$

is oblained. From Eqn (4)

$$
d_{0}=\frac{q_{0}}{4 t L c^{\prime}} \cdot \quad d_{A}=\frac{1}{4} \cdot \frac{q_{0} L}{t c^{\prime}}-\frac{3}{5} f_{6} c^{2}
$$

are obtained. Thus, by using the relationship between the equations, we obtain:

$$
t_{4}=\frac{3}{4} \frac{q_{o}}{t L c} . \quad f_{c}=\frac{1}{2} \frac{q_{o} n}{t L c^{3}}, \quad \dot{\nu}_{2}-\frac{1}{4 n} \frac{q_{o} n c}{t l}-\frac{1}{8} \frac{q_{o} L}{t r}
$$

if we replace these coefficients into Equations (17), (18) and (19), we obtain.

$$
\begin{aligned}
\sigma_{x}= & -\frac{1}{4} \frac{q_{o}}{t L c^{3}} x^{3} y+\frac{1}{2} \frac{q_{o} n}{t l c^{3}} x y^{3}+\frac{1}{4} \frac{q_{o} L}{t c^{3}} x y-\frac{3}{10} \frac{q_{o} n}{t L c} x y \\
\sigma_{y}= & -\frac{1}{4} \frac{q_{o}}{t L c^{3}} x y^{3}+\frac{3}{4} \frac{q_{o}}{t L c} x y-\frac{1}{2} \frac{q_{o}}{t L} x \\
\tau_{x y}= & -\frac{3}{8} \frac{q_{o}}{t L c^{3}} x^{2} y^{2}-\frac{1}{8} \frac{q_{o} n}{t L c^{3}} y^{4}-\frac{1}{8} \frac{q_{o} L}{t c^{3}} y^{2}+\frac{3}{20} \frac{q_{o} n}{t L c} y^{2} \\
& -\frac{3}{8} \frac{q_{o}}{t L c} x^{2}-\frac{1}{40} \frac{q_{o} n c}{t L}+\frac{1}{8} \frac{q_{o} L}{t c}
\end{aligned}
$$

\section{ELASTO-PLASTIC SOLUTION}

During the clastic-plastic solution. the material is 
assumed to be purely plastic, because the analytical solution of the beam is almost impossible under the condition of work hardening. The equations of equilibrium for the plane-stress neglecting body force are given as,

$$
\begin{aligned}
& \frac{\partial \sigma_{x}}{\partial x}+\frac{\partial \tau_{x y}}{\partial y}=0 \\
& \frac{\partial \tau_{x y}}{\partial x}+\frac{\partial \sigma_{y}}{\partial y}=0
\end{aligned}
$$

The composite beam possesses nearly the same yield point in tension and compression due to reinforcing by the steel wires; therefore the Tsai Hill theory is used as a yield criterion in this study. The equivalent stress in a principal material direction is given as,

$$
\bar{\sigma}^{2}=\sigma_{1}^{2}-\sigma_{1} \sigma_{2}+\frac{X^{2}}{Y^{2}} \sigma_{2}^{2}+\frac{X^{2}}{S^{2}} \tau_{12}^{2}-Y^{2}
$$

where $X, Y$ are the yield points in the $1^{\text {si }}$ and $2^{\text {nd }}$ principal material directions respectively and $S$ is the shear yield strength in the 1-2 planc. The stress components in the principal material directions are written as,

$$
\begin{aligned}
& \sigma_{1}=\sigma_{x} \cos ^{2} \theta+2 \tau_{x y} \sin \theta \cos \theta \\
& \sigma_{2}=\sigma_{x} \sin ^{2} \theta-2 \tau_{x y} \sin \theta \cos \theta \\
& \tau_{12}=-\sigma_{x} \sin \theta \cos \theta+\tau_{x y}\left(\cos ^{2} \theta-\sin ^{2} \theta\right)
\end{aligned}
$$

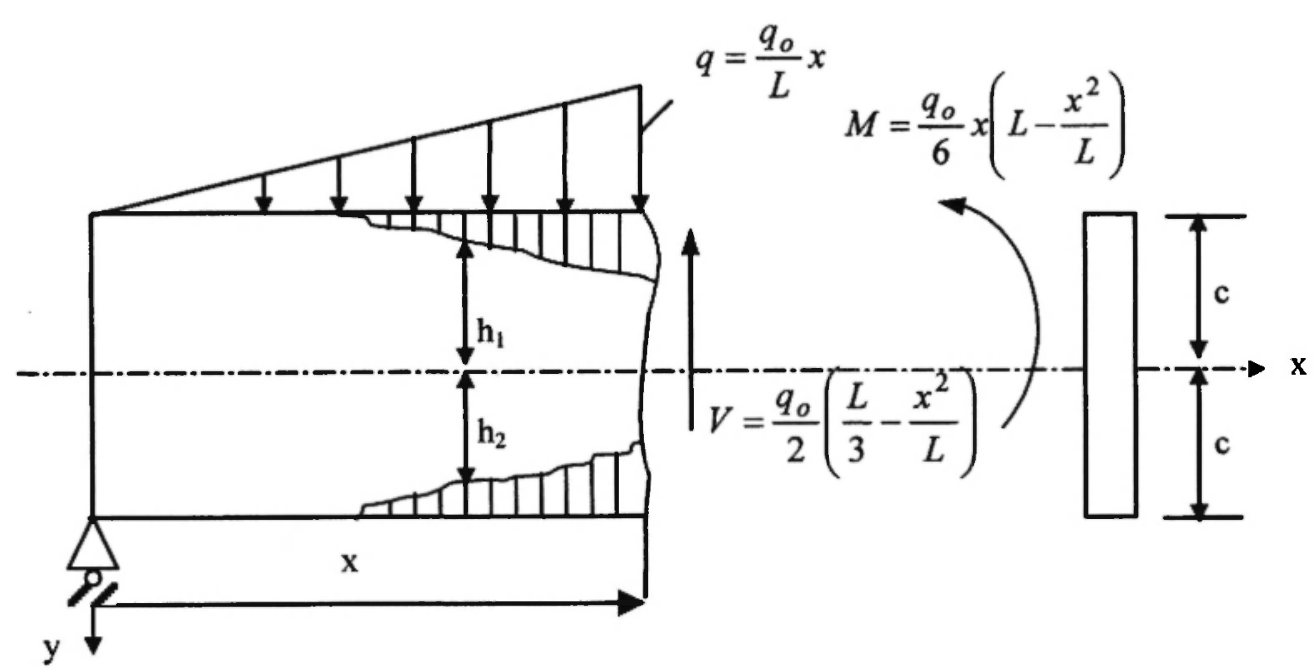

Fig. 2: Simply supported composite cantilever beam subjected to a linearly distributed load for elasto-plastic solution

Writing $\sigma_{y}=0$ in the second differential equations of equilibrium gives that $\tau_{x y}$ is a function of $y$ in the ordinary form or $\tau_{z,}=f(y)$ and $\frac{\partial \tau_{x y}}{\partial x}=0$. And putting the stress components $\sigma_{1}, \sigma_{2}$ and $\tau_{12}$ in Eqn (25) and deriving it with respect to $\mathrm{x}$ gives $\frac{\partial \sigma_{x}}{\partial x}=0$, integration of which gives $\sigma_{x}=f(y)$. The plastic region begins at the lower and upper surfaces of the beam when the stress component $\sigma_{x}$ reaches,

$$
X_{1}=\frac{x}{\sqrt{\cos ^{4} \theta-\sin ^{2} \theta \cos ^{2} \theta+\frac{X^{2} \sin ^{4} \theta}{Y^{2}}+\frac{X^{2} \sin ^{2} \theta \cos ^{2} \theta}{s^{2}}}}
$$

where $\theta$ is the orientation angle of the fibres. When the plastic region starts on these surfaces $\sigma_{x}$ becomes $X_{1}$ and $\tau_{x y}$ equals 0 . From this condition, $\sigma_{x}=X_{1}$ is found as a constant in the plastic region and shear stress is equal to zero.

The composite cantilever beam is loaded by linearly distributed load $q$ for elasto-plastic solution as shown in Figure 2.

The stress function $F$ was given in Eqn (13). The boundary conditions for the elasto-plastic solution are given as

$$
y=-h_{1} \Rightarrow \tau_{x v}=0
$$




$$
\begin{aligned}
& y=h_{2} \Rightarrow \tau_{x y}=0 \\
& \int_{-h_{1}}^{h_{2}} \tau_{x y} l d y=-\frac{q_{o} x^{2}}{2 L} \\
& y=-h_{1} \Rightarrow \sigma_{x}=-X_{1} \\
& y=h_{2} \Rightarrow \sigma_{x}=X_{1}
\end{aligned}
$$

The resultant of $\sigma_{x}$ at any section is equal to zero:

$$
X_{1} t\left(c-h_{1}\right)-X_{1} t\left(c-h_{2}\right)+\int_{-h_{1}}^{h_{2}} \sigma_{x} t d y=0
$$

The resultant moment of $\sigma_{x}$ at any section (x) is equal to the bending moment:

$$
\begin{gathered}
X_{1} t\left(c-h_{1}\right) \frac{c+h_{1}}{2}+X_{\mathrm{i}}+\left(r-h_{-}\right) \frac{c+h_{2}}{2} \\
+\int_{-h_{1}}^{h_{2}} \sigma_{x} t y d y=\frac{q_{o}}{2} x\left(L-\frac{x^{2}}{3 L}\right)
\end{gathered}
$$

$h_{1}$ is equal to $h_{2}$ because of the symmetry of the material properties with respect to the $\mathrm{x}$ axis.

From the boundary conditions, the unknown parameters are found as,

$$
\begin{aligned}
& d_{4}=-d_{6} x^{2}+2 n h_{1}^{2} d_{6}+\frac{X_{1}}{x h} \\
& \frac{1}{2} b_{4} x^{2}+b_{2}=-x^{2} h_{1}^{2} d_{6}-\frac{1}{2} h_{1}^{4} n d_{6}-\frac{1}{2} h_{1} \frac{X_{1}}{x} \\
& d_{6}=\frac{\frac{q_{o} x^{2}}{2 L t}-\frac{2}{3} h_{i}^{2}-\frac{X_{1}}{x}}{\frac{4}{3} x^{2} h_{1}^{3}+\frac{8}{15} n h_{1}^{5}} \\
& X_{1} c^{2}-X_{1} h_{1}^{2}-\frac{8}{15} n x h_{1}^{5} d_{6}+\frac{2}{3} X_{1} h_{1}^{2} \\
& =\frac{1}{2} q_{0} x\left(L-\frac{x^{2}}{3 L}\right)
\end{aligned}
$$

Solving Equation (39) by the Newton-Raphson method gives $h_{1}$ and then the other constants can be determined.

\section{SAMPLE AND DISCUSSION}

During the analytical solution steel fiber-reinforced aluminum metal-matrix composite beams are used as shown in Figure 3 /20\%. Its mechanical properties and

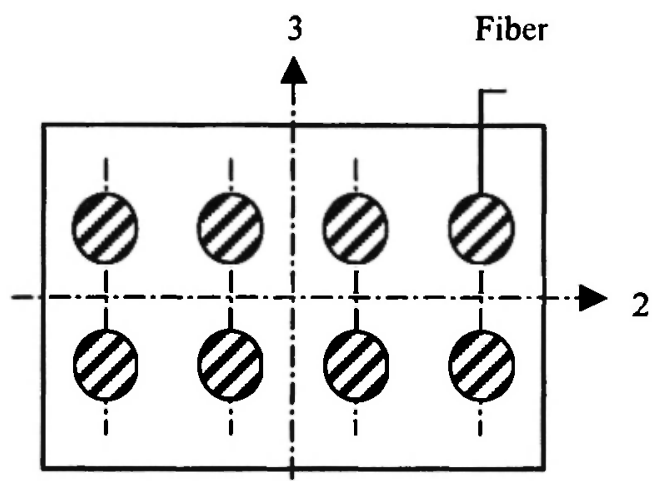

Fig. 3: Final product of the beam

yield points are given in Table 1. The analytical solution is applied to simply supported composite beams subjected to the linearly distributed load. We neglected the stress component $\sigma_{y}$ in comparison with $\sigma_{\mathrm{r}}$ and $\tau_{x v}$, and chose $\mathrm{q}_{\mathrm{o}}$ as $5 \mathrm{~N}$ per mm thickness. Elastoplastic solutions were carried out for orientation angles of $0^{\circ}, 30^{\circ}, 45^{\circ}, 60^{\circ}$ and $90^{\circ}$. The thickness and height of the beam have been taken as 8 and $14 \mathrm{~mm}$ respectively.

Plastic yielding starts first at the upper and lower surfaces for the $0^{\circ}, 30^{\circ}, 45^{\circ}, 60^{\circ}$ and $90^{\circ}$ orientation angles as seen in Table 2 . The plastically collapsed points are determined for each orientation angle. It is maximum for the $0^{\circ}$ orientation angle (Table 3 ). During the solution, the length of the beam, $L$, is chosen smaller than the distance of the collapsed points for each orientation angle. The expansion of the plastic region and the residual stress component of the $\sigma_{x}$ on the upper and lower surfaces are given in Table 4. As seen in this table, $\sigma_{x}$ residual stress component is tensile and compressive on the upper and lower surfaces, respectively. The intensity of the residual stress components of $\sigma_{x}$ is maximum on those surfaces. The residual stress component of the $\tau_{x y}$ is also given at the $\mathrm{x}$ axis in this table, because that is maximum on the $\mathrm{x}$ axis. The intensity of the residual stress component of $\sigma_{\mathrm{r}}$ is maximum for $x=L / \sqrt{3}$. 
Table 1

Mechanical properties and yield strengths of the composite beam.

\begin{tabular}{|c|c|c|c|c|c|c|}
\hline $\begin{array}{c}\mathrm{E}_{1} \\
(\mathrm{MPa})\end{array}$ & $\begin{array}{c}\mathrm{E}_{2} \\
(\mathrm{MPa})\end{array}$ & $\begin{array}{c}\mathrm{G}_{12} \\
(\mathrm{MPa})\end{array}$ & $\mathrm{U}_{12}$ & $\begin{array}{c}\text { Axial Strength } \\
\mathrm{X}(\mathrm{MPa})\end{array}$ & $\begin{array}{c}\text { Transverse } \\
\text { Strength } \\
\mathrm{Y}(\mathrm{MPa})\end{array}$ & $\begin{array}{c}\text { Shear Strength } \\
\mathrm{S}(\mathrm{MPa})\end{array}$ \\
\hline 85000 & 74000 & 30000 & 0.3 & 230.00 & 24.00 & 48.90 \\
\hline
\end{tabular}

Table 2

The lengths of the plastic region at the upper and lower surfaces and length of beams

\begin{tabular}{|c|c|c|c|c|c|c|c|c|c|c|}
\hline $\begin{array}{c}\text { Orientation } \\
\text { Angle }\end{array}$ & \multicolumn{2}{|c|}{$0^{\circ}$} & \multicolumn{2}{|c|}{$30^{\circ}$} & \multicolumn{2}{|c|}{$45^{\circ}$} & \multicolumn{2}{|c|}{$60^{\circ}$} & \multicolumn{2}{|c|}{$90^{\circ}$} \\
\hline $\begin{array}{l}\text { At the upper and } \\
\text { lower surface }\end{array}$ & 154.0 & 418.0 & 87.3 & 231.0 & 68.0 & 178.0 & 58.0 & 149.1 & 50.4 & 133.9 \\
\hline Length of beam & \multicolumn{2}{|c|}{510.000} & \multicolumn{2}{|c|}{285.000} & \multicolumn{2}{|c|}{220.000} & \multicolumn{2}{|c|}{185.000} & \multicolumn{2}{|c|}{165.000} \\
\hline
\end{tabular}

iij

Table 3

Yield points, and length of the plastic collapse

\begin{tabular}{|c|c|c|c|c|c|}
\hline Orientation Angles & $0^{\circ}$ & $30^{\circ}$ & $45^{\circ}$ & $60^{\circ}$ & $90^{\circ}$ \\
\hline $\mathrm{X}_{1}$ & 230.000 & 71.800 & 43.090 & 30.822 & 24.000 \\
\hline Length $(\mathrm{mm})$ & 530.000 & 296.227 & 229.487 & 194.000 & 171.400 \\
\hline
\end{tabular}

The distribution of the residual stress components of $\sigma_{x}$ is given for the $0^{\circ}, 30^{\circ}, 45^{\circ}, 60^{\circ}$ and $90^{\circ}$ orientation angles as shown in Figure 4. The residual stress component of $\sigma_{x}$ is represented along the cross section of the beam at some sections.

\section{CONCLUSIONS}

The results given below are concluded in this investigation.

- The magnitude of the residual stress component of $\sigma_{x}$ is maximum at the upper and lower surfaces. It is maximum for $0^{\circ}$ orientation angle.

- When the orientation angle is increased, the plastic region starts at smaller distances.

- The magnitude of the residual stress component of $\sigma_{x}$ at the upper and lower surfaces is the same for $0^{\circ}, 30^{\circ}, 45^{\circ}, 60^{\circ}$ and $90^{\circ}$ orientation angles because of the symmetry of the material properties with respect to the $\mathrm{x}$ axis.

- The magnitude of the residual stress component of $\tau_{x y}$ is greatest on or around the $\mathrm{x}$ axis. It is much smaller than that of $\sigma_{x}$.

- The plastic collapse occurs first for $90^{\circ}$ oriented beam. It is largest for $0^{\circ}$ oriented beam.

- Plastic yielding occurs at the greatest distance from the end for the $0^{\circ}$ orientation angle. It is smaller for $90^{\circ}$ orientation angle.

- The magnitude The strength of the beam is increased by residual stresses. of the residual stress component of $\sigma_{x}$ is maximum for $x=L / \sqrt{3}$

- The strength of the beam is increased by residual stresses. 
Table 4

The residual stress component of $\sigma_{x}$ at the upper and lower surfaces and $\tau_{x y}$ on the $\mathrm{x}$ axis

\begin{tabular}{|c|c|c|c|c|c|c|c|c|c|}
\hline$\theta$ & $\begin{array}{c}x \\
(\mathrm{~mm})\end{array}$ & $\begin{array}{c}h_{1} \\
(\mathrm{~mm})\end{array}$ & $\begin{array}{c}\sigma_{\mathrm{x}} \\
(\mathrm{MPa}) \\
\text { at upper } \\
\text { surface }\end{array}$ & $\begin{array}{c}\sigma_{\mathrm{x}} \\
(\mathrm{MPa}) \\
\text { at upper } \\
\text { surface }\end{array}$ & $\begin{array}{c}\sigma_{x_{r}} \\
(\mathrm{MPa}) \\
\text { at upper } \\
\text { surface }\end{array}$ & $\begin{array}{c}\sigma_{x_{p}} \\
(\mathrm{MPa}) \\
\text { at lower } \\
\text { surface }\end{array}$ & $\begin{array}{c}\sigma_{x_{i}} \\
(\mathrm{MPa}) \\
\text { at lower } \\
\text { surface }\end{array}$ & $\begin{array}{c}\sigma_{x_{r}} \\
(\mathrm{MPa}) \\
\text { at lower } \\
\text { surface }\end{array}$ & $\begin{array}{c}\tau_{x y r} \\
(\mathrm{MPa}) \\
\text { on the } \\
x \text { axis }\end{array}$ \\
\hline \multirow{7}{*}{$0^{\circ}$} & 204.44 & 5.30 & -279.106 & -230.000 & 49.106 & 279.106 & 230.000 & -49.106 & 0.676 \\
\hline & 234.44 & 4.34 & -300.762 & -230.000 & 70.762 & 300.762 & 230.000 & -70.762 & 3.737 \\
\hline & 264.44 & 3.60 & -314.504 & -230.000 & 84.504 & 314.504 & 230.000 & -84.504 & 7.826 \\
\hline & 294.44 & 3.31 & -319.316 & -230.000 & 89.316 & 319.316 & 230.000 & -89.316 & 12.03 \\
\hline & 324.44 & 3.62 & -314.188 & -230.000 & 84.188 & 314.188 & 230.000 & -84.188 & 14.58 \\
\hline & 354.44 & 4.47 & -298.105 & -230.000 & 68.105 & 298.105 & 230.000 & -68.105 & 15.47 \\
\hline & 384.44 & 5.65 & -270.056 & -230.000 & 40.056 & 270.056 & 230.000 & -40.056 & 16.03 \\
\hline \multirow{7}{*}{$30^{\circ}$} & 104.54 & 5.89 & -82.269 & -71.800 & 10.469 & 82.269 & 71.800 & -10.469 & -0.371 \\
\hline & 124.54 & 4.69 & -91.624 & -71.800 & 19.824 & 91.624 & 71.800 & -19.824 & 1.362 \\
\hline & 144.54 & 3.71 & -97.635 & -71.800 & 25.835 & 97.635 & 71.800 & -25.835 & 3.905 \\
\hline & 164.54 & 3.30 & 99.765 & -71.800 & 27.965 & 99.765 & 71.800 & -27.965 & 6.747 \\
\hline & 184.54 & 3.75 & -97.476 & -71.800 & 25.676 & 97.476 & 71.800 & -25.676 & 8.289 \\
\hline & 204.54 & 4.89 & -90.232 & -71.800 & 18.432 & 90.232 & 71.800 & -18.432 & 8.771 \\
\hline & 224.54 & 6.43 & -77.495 & -71.800 & 5.695 & 77.495 & 71.800 & -5.695 & 9.191 \\
\hline \multirow{7}{*}{$45^{\circ}$} & 87.010 & 5.46 & -51.539 & -43.090 & 8.449 & 51.539 & 43.090 & -8.449 & 0.175 \\
\hline & 97.010 & 4.72 & -54.875 & -43.090 & 11.785 & 54.875 & 43.090 & -11.785 & 1.102 \\
\hline & 107.010 & 4.08 & -57.367 & -43.090 & 14.277 & 57.367 & 43.090 & -14.277 & 2.278 \\
\hline & 127.010 & 3.44 & -59.473 & -43.090 & 16.383 & 59.473 & 43.090 & -16.383 & 4.996 \\
\hline & 147.010 & 4.14 & -57.160 & -43.090 & 14.070 & 57.160 & 43.090 & -14.070 & 6.396 \\
\hline & 157.010 & 4.90 & -54.130 & -43.090 & 11.040 & 54.130 & 43.090 & -11.040 & 6.657 \\
\hline & 167.010 & 5.84 & -49.734 & -43.090 & 6.624 & 49.734 & 43.090 & -6.624 & 6.879 \\
\hline \multirow{7}{*}{$60^{\circ}$} & 76.809 & 5.27 & -37.550 & -30.822 & 6.728 & 37.550 & 30.822 & -6.728 & 0.422 \\
\hline & 86.809 & 4.47 & -39.950 & -30.822 & 9.168 & 39.950 & 30.822 & -9.168 & 1.436 \\
\hline & 96.809 & 3.89 & -41.533 & -30.822 & 10.711 & 41.533 & 30.822 & -10.711 & 2.685 \\
\hline & 106.809 & 3.66 & -42.075 & -30.822 & 11.253 & 42.075 & 30.822 & -11.253 & 3.950 \\
\hline & 116.809 & 3.90 & -41.512 & -30.822 & 10.690 & 41.512 & 30.822 & -10.690 & 4.838 \\
\hline & 126.809 & 4.57 & -39.740 & -30.822 & 8.918 & 39.740 & 30.822 & -8.918 & 5.304 \\
\hline & 136.809 & 5.54 & -36.658 & -30.822 & 5.836 & 36.658 & 30.822 & -5.836 & 5.804 \\
\hline \multirow{7}{*}{$90^{\circ}$} & 6.260 & 5.36 & -29.013 & -24.000 & 5.013 & 29.013 & 24.000 & -5.013 & 0.152 \\
\hline & 75.260 & 4.35 & -31.415 & -24.000 & 7.415 & 31.415 & 24.000 & -7.415 & 1.158 \\
\hline & 85.260 & 3.56 & -32.944 & -24.000 & 8.944 & 32.944 & 24.000 & -8.944 & 2.535 \\
\hline & 95.260 & 3.24 & -33.485 & -24.000 & 9.485 & 33.485 & 24.000 & -9.485 & 3.979 \\
\hline & 105.260 & 3.59 & -32.921 & -24.000 & 8.921 & 32.921 & 24.000 & -8.921 & 4.792 \\
\hline & 115.260 & 4.49 & -31.137 & -24.000 & 7.137 & 31.137 & 24.000 & -7.137 & 5.058 \\
\hline & 125.260 & 5.74 & -28.016 & -24.000 & 4.016 & 28.016 & 24.000 & -4.016 & 5.228 \\
\hline
\end{tabular}



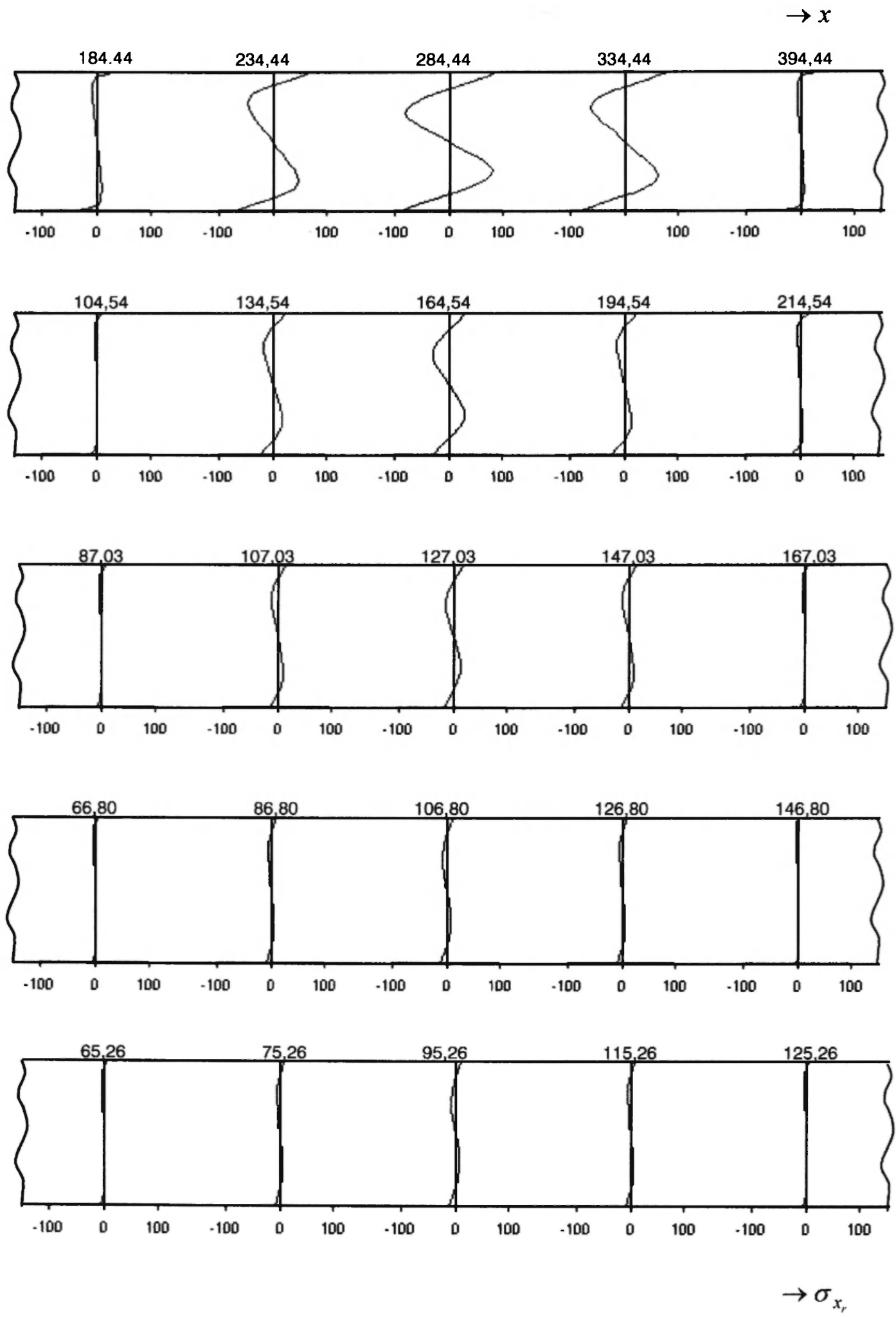

Fig. 4: Distribution of the residual stress component of $\sigma_{x}$ along the sections for $0^{\circ}, 30^{\circ}, 45^{\circ}, 60^{\circ}$ and $90^{\circ}$ orientation angles, respectively 


\section{REFERENCES}

1. T.W. Chou, A. Kelly and A. Okura. Fibrereinforced metal-matrix composites, Journal of Composite Materials, 16: 187-206 (1985).

2. J.W. Kaczmar, K. Pietrzak and W. Wlosinski. The production and application of metal matrix composite materials, Journal of Materials Processing Technology, 106: 58-67 (2000).

3. M. Khatibzadeh and M.R. Piggott. The effect of width on the mechanical properties of the angleply laminates, Composite Science and Technology, 58: 497-504 (1998).

4. Y.A. Bahei-El-Din and G.J. Dvorak. Plasticity analysis of laminated composite plates, Transactions of the ASME, 49: 740-746 (1982).

5. C.C. Kang and S.S. Kang. Effect of extrusion on fibre orientation and breakage of alumina short fibre composites, Journal of Composite Materials, 28:155-166 (1994).

6. N.M. Yeh and E. Krempl. The influence of cooldown temperature histories on the residual stresses in fibrous metal-matrix composites, Journal of Composite Materials, 27:973-995 (1983).

7. O. Sayman and M. Kayricı. An elastic-plastic stress analysis in a thermoplastic composite cantilever beam, Composites Science and Technology, 60: 623-631 (2000).

8. Ü. Esendemir. An elasto-plastic stress analysis in a thermoplastic composite beam of arbitrary orientation subjected to transverse uniformly distributed load, International Journal of Applied Mechanics and Engineering, 6(2):325-344 (2001).

9. Ü. Esendemir. An elasto-plastic stress analysis in a polymer matrix composite beam of arbitrary orientation subjected to transverse linearly distributed load, Journal of Reinforced Plastics and Composites, 21(8): 735-748 (2002).

10. O. Sayman. An elastic-plastic stress analysis of metal-matrix composite beam loaded transversely, Journal of Reinforced Plastic and Composites, 20: 639-651 (2001).
11. R. Karakuzu and R. Özcan. Exact solution of elasto-plastic stresses in metal matrix composite beam of arbitrary orientation subjected to transverse loads, Composite Science and Technology, 56: 1383-1389 (1997).

12. M. Küçü̉k, H. Akbulut and Ü. Esendemir. An elastic-plastic stress analysis of aluminum metalmatrix composite beams supported from two ends with a force acted at the mid point, Journal of Reinforced Plastic and Composites, 21(13): 13631375 (2002).

13. O. Sayman and M. Zor. An analytical elasticplastic stress analysis in a woven steel reinforced thermoplastic cantilever beam loaded uniformly, Composites: Part B, 31: 277-284 (2000).

14. O. Sayman and M. Zor. Elastic-plastic stress analysis and residual stresses in a woven steel fiber reinforced thermoplastic composite cantilever beam loaded uniformly, Journal of Reinforced Plastics and Composites, 19(13): 1079-1092 (2000).

15. O. Sayman and H. Callıoglu. An elastic-plastic stress analysis of thermoplastic composite beams loaded by bending moments, Composite Structures, 50: 199-205 (2000).

16. O. Sayman, S. Aksoy and H. Aykul. An elasticplastic solution for a thermoplastic composite cantilever beam loading by bending moment, Composites Science and Technology, 60: 27392745 (2000).

17. S.G. Lekhnitskii. Theory of elasticity of an anisotropic body, Mir Publishers, Moscow, 1981.

18. S.G. Lekhnitskii. Anisotropic plates, Gordon and Breach Science Publishers, 1968.

19. R.M. Jones. Mechanics of composite materials, McGraw-Hill Kogakusha, Tokyo, 1975.

20. O. Sayman and Ü. Esendemir. An elastic-plastic stress analysis of simply supported metal matrix composite beams under a transverse uniformly distributed load, Composites Science and Technology, 62:256-273 (2002). 
1. 